Jurnal Ekonomi dan Industri

Volume 20, No. 1, Januari-April 2019

p-ISSN : 0853-5248

\title{
PENGARUH PENEMPATAN DAN LINGKUNGAN KERJA TERHADAP PRESTASI KERJA KARYAWAN PT. JELAJAH LAUT NUSANTARA JAKARTA
}

\author{
Muh Kausar Maulana*) \\ *) Dosen Program Studi Manajemen FE UNKRIS \\ Alamat: Kampus UNKRIS, Jatiwaringin Jakarta Timur \\ Email : Kausarmaulana@yandex.com
}

\begin{abstract}
Achievement in work is one of the needs that everyone wants to achieve at work. One of the factors that can affect one's work performance in achieving work targets by placing the right employees in accordance with the abilities and skills possessed and support from the work environment around the employees. This study aims to analyze the presence or absence of influence both simultaneously and partially placement and work environment on employee performance at PT. Archipelago Sea Exploration Jakarta involving 100 respondents. The results of the study indicate that there are influences both simultaneously and partially in the placement and work environment of the work performance of employees at PT. Nusantara Sea Cruising Jakarta.
\end{abstract}

Ke words : Placement, work environment and work performance

\section{PENDAHULUAN}

Prestasi dalam bekerja merupakan salah satu kebutuhan yang ingin dicapai setiap orang dalam bekerja. Prestasi kerja karyawan tidak sama hasilnya, hal ini disebabkan karena setiap karyawan mempunyai kemampuan dan kemauan yang berbeda untuk melaksanakan pekerjaan. Prestasi kerja seseorang merupakan ukuran keberhasilan suatu proses yang yang dihasilkan oleh tiap individu. Penilaian prestasi kerja dilakukan bersama pimpinan dan bawahannya. Kinerja sebuah perusahaan merupakan kegiatan yang dilakukan untuk meningkatkan eksistensi perusahaan dalam mencapai tujuan dan sasaran sesuai dengan visi dan misinya. Kinerja perusahaan dilakukan dalam menjamin tercapainya sasaran yang ditetapkan perusahaan itu sendiri. Kinerja perusahaan dilakukan untuk mengetahui posisi perusahaan jika terjadi kelambatan, harus segera dicari penyebabnya untuk segera diupayakan mengatasinya. Masalah ketidakpuasan individu dalam bekerja akan memberikan dampak langsung terhadap hasil kerja yang dicapai tiap individu. Hal ini berdampak jika seseorang sudah merasakan kepuasan dalam bekerja maka individu tersebut akan selalu berusaha untuk memberikan hasil yang terbaik, begitu juga sebaliknya jika individu yang bersangkutan belum merasakan kepuasan dalam bekerja artinya apa yang didapatkan dari perusahaan tidak sesuai dengan harapan maka akan memberikan dampak menurunnya semangat dan pengembangan karyawan dalam bekerja.

Lingkungan kerja merupakan salah satu faktor yang dapat membentuk tinggi rendahnya prestasi kerja seseorang. Pernyataan ini didukung oleh hasil penelitian yang dilakukan oleh Andi Nurhasanah (2010) dalam penelitiannya membuktikan bahwa ada pengaruh lingkungan kerja dalam pembentukan tinggi rendahnya prestasi kerja seseorang. Dalam penelitiannya diungkap bahwa prestasi kerja dicerminkan pada seberapa besar tanggungjawab seorang individu agar mampu melaksanakan pekerjaan yang diberikan dan pada akhirnya akan bermuara pada penyusunan program pelatihan yang akan dilakukan. 
Untuk variabel lingkungan kerja dicerminkan pada lingkungan kerja fisik dan lingkungan kerja nonfisik.

Selain lingkungan kerja, faktor penempatan karyawan juga ikut memberikan kontribusi dalam pembentukan prestasi kerja individu karyawan. Pernyataan ini seperti hasil penelitian yang dilakukan oleh Cindy Rahmawati, et all (2015) yang mengemukakan bahwa terdapat pengaruh yang positif dan signifikan penempatan terhadap prestasi kerja pegawai. Penempatan karyawan yang tepat dapat mendukung keberhasilan setiap individu dalam mencapai target pekerjaan. Oleh karena itu dengan tercapainya target pekerjaan akan memberikan dampak bagi pencapaian tujuan dan sasaran perusahaan.

\section{LANDASAN TEORI}

\section{Penempatan}

Rosidah (2009) mendefinisikan penempatan "sebagai suatu kebijakan yang diambil oleh pimpinan suatu instansi, atau bagian personalia untuk menentukan seseorang pegawai masih tetap atau tidak ditempatkan pada suatu posisi atau jabatan tertentu berdasarkan pertimbangan keahlian, keterampilan atau kualifikasi tertentu". Rivai (2009) mendefinisikan penempatan pegawai adalah "penugasan atau penugasan kembali seorang pegawai kepada pekerjaan barunya". Siagian (2008) mengungkapkan "penempatan tidak hanya berlaku bagi para pegawai baru, akan tetapi berlaku pula bagi pegawai lama yang mengalami alih tugas dan mutasi”.

Dimensi yang digunakan mengukur penempatan pegawai menggunakan dimensi penempatan yang dikemukakan oleh Siagian (2005:19) adalah: 1) "Pengetahuan adalah kumpulan fakta-fakta yang dimiliki manusia setelah melakukan usaha pengamatan dan pemikiran dan dapat terakumulasi. 2) Minat adalah perhatian, kesukaan, kecenderungan hati seseorang yang mengandung unsur-unsur perasaan yang dapat menentukan suatu sikap yang menyebabkan seseorang aktif dalam kegiatan tertentu. 3) Keterampilan adalah kecakapan seseorang dalam menyelesaikan tugas-tugasnya. 4) Pengalaman adalah sesuatu keahlian khusus yang sudah dimiliki oleh seseorang dan sudah pernah dialami oleh seseorang tersebut”.

\section{Lingkungan kerja}

Sutrisno (2009) mengemukakan bahwa "lingkungan kerja merupakan keseluruhan sarana dan prasarana kerja yang ada di sekitar pegawai yang sedang melaksanakan pekerjaan yang dapat mempengaruhi pelaksanaan pekerjaan”. Lingkungan kerja ini meliputi tempat bekerja, fasilitas dan alat bantu pekerjaan, kebersihan, pencahayaan, ketenangan termasuk juga hubungan antara orang-orang yang ada ditempat tersebut. Sofyandi (2008:82) mendefinisikan lingkungan kerja sebagai lingkungan dimana pegawai melakukan pekerjaannya sehari-hari. Sedarmayanti (2011) menyatakan bahwa "lingkungan kerja dapat diukur melalui indikator lingkungan kerja fisik dan lingkungan kerja non fisik".

\section{Prestasi kerja}

Prestasi kerja didefinisikan oleh Sondang (2008) sebagai "penilaian yang berperan sebagai umpan balik tentang berbagai hal seperti kemampuan, keletihan, kekurangan dan potensinya yang pada gilirannya bermanfaat untuk menentukan tujuan, jalur rencana dan pengembangan karier". Sirait (2007) mengungkapkan prestasi kerja adalah "proses evaluasi prestasi atau hasil kerja pegawai yang dilakukan oleh perusahaan". Menurut Mondy (2008) prestasi kerja diartikan "sebagai suatu sistem untuk meninjau dan 
mengevaluasi hasil kerja pegawai”. Sirait (2007) mengemukakan bahwa terdapat beberapa aspek yang harus diperhatikan dalam mengukur prestasi kerja pegawai antara lain 1) "Kualitas kerja. Kualitas kerja dapat diukur berdasarkan penguasaan ilmu pengetahuan dan teknologi yang dimiliki pegawai yang ada di dalamnya menyangkut pemberian kesempatan pegawai untuk mengikuti diklat, kursus-kursus, dan pelatihan yang menunjang peningkatan kinerja. Kualitas kerja juga dapat diukur melalui pemahaman pegawai akan lingkup pekerjaannya, pemahaman pegawai akan lingkup pekerjaannya, pemahaman akan tanggungjawab dan wewenang yang diemban, ketepatan, ketelitian, keterampilan, dan keberhasilan. 2) Kuantitas kerja. Kuantitas kerja dapat diukur melalui tingkat keluaran hasil atau output serta kecepatan pegawai dalam menyelesaikan pekerjaan. 3) Konsistensi karyawan. Konsistensi karyawan dapat diukur diantaranya dari pengembangan kemampuan dan aktualisasi diri yang dilakukannya misalnya selalu mengikuti perkembangan ilmu pengetahuan dan teknologi, selalu berkeinginan untuk menambah wawasan dan keinginan untuk maju".

\section{METODE PENELITIAN}

Populasi dalam penelitian ini adalah karyawan PT. Jelajah Laut Nusantara Jakarta sebanyak 100 orang karyawan.

Tehnik pengambilan sampel yang digunakan dalam penelitian ini yaitu sampel jenuh. Berdasarkan tehnik sampling yang digunakan maka jumlah sampel penelitian ini yaitu sebanyak 100 orang.

Metode yang digunakan dalam penelitian ini adalah metode deskriptif dengan menggunakan pendekatan kuantitatif. Penelitian ini juga menekankan analisisnya pada data-data numerik yang diolah menggunakan metode statistika denan regresi berganda dan sederhana.

\section{HASIL DAN PEMBAHASAN}

\section{Hasil Penelitian}

\section{Uji Instrumen Data}

\section{Uji Validitas}

Penguji validitas ini dilakukan untuk menguji apakah tiap-tiap butir pernyataan telah mewakili indikator yang akan diselidiki. Menurut Masrun yang dikutip oleh Sugiyono, 2014, menyatakan bahwa "syarat minimum untuk dianggap valid adalah $r=$ 0,30". Jadi apabila korelasi antara butir-butir dengan skor total kurang dari 0,30 maka butiran dalam instrument tersebut dinyatakan tidak valid. Uji validitas dilakukan dengan melihat korelasi antar skor masing-masing item pernyataan dengan skor total.

\section{a. Uji Validitas Instrumen Kompetensi}

Dari hasil perhitungan korelasi skor tiap butir pernyataan instrument penempatan dari 100 responden dengan jumlah pernyataan masing-masing variabel 10 pernyataan dengan total skor setiap responden diperoleh hasil disajikan dalam tabel sebagai berikut : 
Tabel 3. Uji Validitas Variabel Penempatan

\begin{tabular}{cccc}
\hline Kuesioner & R hitung & Rkritis & Kesimpulan \\
\hline Instrumen No. 1 & 0.936 & 0,202 & Valid \\
Instrumen No. 2 & 0.924 & 0,202 & Valid \\
Instrumen No. 3 & 0.914 & 0,202 & Valid \\
Instrumen No. 4 & 0.945 & 0,202 & Valid \\
Instrumen No. 5 & 0.912 & 0,202 & Valid \\
Instrumen No. 6 & 0.862 & 0,202 & Valid \\
Instrumen No. 7 & 0.954 & 0,202 & Valid \\
Instrumen No. 8 & 0.960 & 0,202 & Valid \\
Instrumen No. 9 & 0.789 & 0,202 & Valid \\
Instrumen No. 10 & 0.933 & 0,202 & Valid
\end{tabular}

Berdasarkan tabel 3, dapat dilihat bahwa dari 10 butir pernyataan dari variabel penempatan hasilnya adalah valid.

\section{b. Uji Validitas Instrumen Penempatan}

Dari hasil perhitungan koefisien korelasi skor tiap butir pernyataan instrument lingkungan kerja dari 100 responden dengan jumlah pernyataan masing-masing variabel 10 pernyataan dengan total skor setiap responden hasil disajikan dalam tabel sebagai berikut

Tabel 4. Uji Validitas Instrumen Lingkungan Kerja

\begin{tabular}{cccc}
\hline Kuesioner & R hitung & R kritis & Kesimpulan \\
\hline Instrumen No. 1 & 0.846 & 0,202 & Valid \\
Instrumen No. 2 & 0.954 & 0,202 & Valid \\
Instrumen No. 3 & 0.901 & 0,202 & Valid \\
Instrumen No. 4 & 0.943 & 0,202 & Valid \\
Instrumen No. 5 & 0.934 & 0,202 & Valid \\
Instrumen No. 6 & 0.858 & 0,202 & Valid \\
Instrumen No. 7 & 0.939 & 0,202 & Valid \\
Instrumen No. 8 & 0.958 & 0,202 & Valid \\
Instrumen No. 9 & 0.954 & 0,202 & Valid \\
Instrumen No. 10 & 0.911 & 0,202 & Valid
\end{tabular}

Berdasarkan tabel 4, dapat dilihat bahwa dari 10 butir pernyataan dari variabel lingkungan kerja hasilnya adalah valid.

\section{c. Uji Validitas Instrumen Prestasi Kerja}

Dari hasil perhitungan koefisien korelasi skor tiap butir pernyataan instrumen prestasi kerja dari 100 responden dengan jumlah pernyataan masing-masing variabel 10 pernyataan dengan total skor setiap responden hasil disajikan dalam tabel 5 
Tabel 5. Uji Validitas Instrumen Prestasi Kerja

\begin{tabular}{cccc}
\hline Kuesioner & R hitung & Rkritis & Kesimpulan \\
\hline Instrumen No. 1 & 0.955 & 0,202 & Valid \\
Instrumen No. 2 & 0.939 & 0,202 & Valid \\
Instrumen No. 3 & 0.931 & 0,202 & Valid \\
Instrumen No. 4 & 0.920 & 0,202 & Valid \\
Instrumen No. 5 & 0.957 & 0,202 & Valid \\
Instrumen No. 6 & 0.926 & 0,202 & Valid \\
Instrumen No. 7 & 0.959 & 0,202 & Valid \\
Instrumen No. 8 & 0.877 & 0,202 & Valid \\
Instrumen No. 9 & 0.863 & 0,202 & Valid \\
Instrumen No. 10 & 0.890 & 0,202 & Valid \\
\hline \multicolumn{2}{l}{ Sumber : Data Primer, diolah tahun 2018 }
\end{tabular}

Berdasarkan tabel 5, dapat dilihat bahwa dari 10 butir pernyataan dari variabel prestasi kerja hasilnya adalah valid.

\section{Hasil Analisis}

Hasil analisis regresi berganda menjelaskan bahwa persamaan regresi yang disusun yaitu $\mathrm{Y}=1.181+0.376\left(\mathrm{X}_{1}\right)+0.419\left(\mathrm{X}_{2}\right)$. Koefisien regresi penempatan bertanda positif dan signifikan, artinya penempatan yang menyebabkan kenaikan sebesar 0.376 terhadap prestasi kerja. Hal ini menunjukkan dengan adanya keberhasilan penempatan karyawan di PT. Jelajah Laut Nusantara Jakarta maka prestasi kerja dari tiap individu karyawan dapat meningkat. Koefisien regresi lingkungan kerja bertanda positif dan signifikan, artinya lingkungan kerja yang menyebabkan kenaikan sebesar 0.419 terhadap prestasi kerja. Hal ini menunjukkan dengan adanya pembentukan lingkungan kerja yang kondusif di PT. Jelajah Laut Nusantara Jakarta dapat meningkatkan prestasi kerja dari tiap individu karyawan.

Nilai $\mathrm{F}$ hitung $=8,238$ lebih besar dibandingkan dengan $\mathrm{F}$ tabel 3.09 atau tingkat signifikan $=0.000$ jauh lebih kecil dari 0.05 , maka dapat diartikan terdapat pengaruh secara signifikan penempatan dan lingkungan kerja terhadap prestasi kerja karyawan di PT. Jelajah Laut Nusantara Jakarta.

Hasil analisis regresi sederhana menjelaskan bahwa persamaan regresi yang disusun yaitu $\mathrm{Y}=1.986+0.702\left(\mathrm{X}_{1}\right)$. Koefisien regresi penempatan bertanda positif dan signifikan menunjukkan penempatan yang menyebabkan kenaikan sebesar 0.702 terhadap prestasi kerja. Hal ini menunjukkan keberhasilan program penempatan karyawan di PT. Jelajah Laut Nusantara Jakarta, maka prestasi kerja karyawan akan semakin meningkat.

Hasil analisis regresi sederhana menjelaskan bahwa persamaan regresi yang disusun yaitu $\mathrm{Y}=1.879+0.876\left(\mathrm{X}_{2}\right)$. Koefisien regresi lingkungan kerja bertanda positif dan signifikan menunjukkan lingkungan kerja yang menyebabkan kenaikan sebesar 0,876 terhadap prestasi kerja karyawan. Hal ini menunjukkan dengan adanya keberhasilan peningkatan lingkungan kerja yang kondusif di PT. Jelajah Laut Nusantara Jakarta akan meningkatkan prestasi kerja. 


\section{KESIMPULAN DAN SARAN}

\section{Kesimpulan}

1). Hasil penelitian menunjukkan bahwa penempatan dan lingkungan kerja berpengaruh secara simultan terhadap prestasi kerja pada PT. Jelajah Laut Nusantara Jakarta. Hal ini berarti bahwa makin tinggi keberhasilan program penempatan dan pembentukan lingkungan kerja yang kondusif maka makin baik prestasi kerja individu karyawan. 2). Hasil penelitian menunjukkan bahwa penempatan berpengaruh terhadap prestasi kerja karyawan PT. Jelajah Laut Nusantara Jakarta. Hal ini berarti bahwa makin tepat penempatan karyawan maka makin baik prestasi kerja karyawan. 3). Hasil penelitian menunjukkan bahwa lingkungan kerja berpengaruh terhadap prestasi kerja karyawan PT. Jelajah Laut Nusantara Jakarta. Hal ini berarti bahwa makin baik lingkungan kerja maka makin baik prestasi kerja karyawan.

\section{Saran}

Setelah mengetahui pengaruh yang diberikan oleh variabel penempatan dan lingkungan kerja terhadap prestasi kerja karyawan PT. Jelajah Laut Nusantara Jakarta. Pada kesempatan ini peneliti mencoba untuk memberikan saran yang sekiranya dapat dijadikan rekomendasi khususnya bagi manajemen PT. Jelajah Laut Nusantara Jakarta, yang dijadikan objek penelitian, maupun perusahaan sejenis dalam mengambil kebijakan-kebijakan untuk peningkatan prestasi kerja karyawannya: 1). Untuk faktor penempatan diharapkan manajemen dapat objektif dalam menempatkan karyawan karena akan memberikan dampak bagi kinerja karyawan. Ketidak sesuaian posisi jabatan yang ditawarkan dengan kemampuan dan minat yang dimiliki akan memberikan dampak langsung bagi tinggi rendahnya hasil kerja karyawan dalam mengemban pekerjaan yang diberikan kepadanya. 2) untuk faktor lingkungan kerja diharapkan manajemen dapat menciptakan lingkungan kerja yang kondusif. Dengan terciptanya lingkungan kerja yang kondusif selain hasil kerja dari tiap individu karyawan tercapai akan memberikan dampak juga bagi loyalitas kerja karyawan dalam hal ini adalah karyawan pada PT. Jelajah Laut Nusantara Jakarta

\section{DAFTAR PUSTAKA}

Andi Nurhasanah., 2010. Pengaruh Lingkungan Kerja Terhadap Prestasi Kerja Karyawan Pada Bank Indonesia Cabang Samarinda.

Charmine., 2007. Human Resource Management. Pearson Education. Australia.

Dessler, Gary, 2011. Manajemen sumber daya manusia. Penerbit Indeks, Jakarta.

Edi Sutrisno., 2009. Manajemen Sumber Daya Manusia Edisi pertama. Kencana Prenada Media Group. Jakarta.

Garry Dessler, 2008. Human Resource Management Edisi Sebelas, : Pearson Education, Inc. New Jersey.

Mangkunegara., 2013, Manajemen Sumber Daya Manusia Perusahaan, Remaja Rosdakarya, Bandung.

Mondy R Wayne., 2008. Manajemen Sumber Daya Manusia. Erlangga. Jakarta.

Pabundu.,2006, Budaya Organisasi dan Peningkatan Kinerja Perusahaan, Cetakan Pertama, PT Bumi Aksara. Jakarta.

Rahmawati Cindy,et al,. 2015. Analisis Rasio Keuangan Terhadap Kondisi Financial Distress Pada Perusahaan Manufaktur Yang Terdaftar Di Bursa Efek Indonesia 
Tahun 2008-2013. Syariah Paper Accounting FEB. Universitas Muhammadiyah Surakarta.

Sedarmayanti., 2008. Sumber Daya Manusia dan Produktivitas Kerja: CV Mandar Maju. Bandung.

Sofyandi., 2008, Manajemen Sumber Daya Manusia, Edisi Pertama,Penerbit Graha Ilmu, Yogyakarta.

Simamora., Henry, 2004, Manajemen Sumber Daya Manusia, Edisi Ketiga, Cetakan Pertama, Bagian Penerbitan STIE YKPN, Yogyakarta.

Siagian.,2008.Manajemen Sumber Daya Manusia Bumi Aksara. Jakarta.

Sulistiyani dan Rosidah., 2003, Manajemen Sumber Daya Manusia,Graha Ilmu Yogyakarta.

Siagian, P. Sondang., 2005. Fungsi-fungsi Manajemen. Jakarta. Penerbit Bumi Aksara.

Sirait., 2007 Memahami Aspek-aspek Pengelolaan Sumber Daya Manusia dalam. Organisasi.Gramedia Widiasarana Indonesia, Jakarta.

The Liang Gie., 2007. Administrasi Perkantoran Modern. Liberty. Yogyakarta.

Umar., 2008. Metode Penelitian Untuk Skripsi dan Tesis Bisnis. PT Rajagrafindo Persada. Jakarta.

Veithzal. Rivai., 2009. Manajemen Sumber Daya Manusia Untuk Perusahaan Dari Teori ke Praktik. Raja Grafindo Persada. Jakarta.

Yuniarsih, Suwanto., 2009. Manajemen Sumber Daya Manusia Teori,Aplikasi, Dan Isu Penelitian. Alfabeta. Bandung. 